\title{
0 rio e a montanha: uma análise comparativa das fontes budistas em Sidarta de Hermann Hesse e Os vagabundos iluminados de Jack Kerouac
}

\author{
Jorge Gonçalves de Oliveira Júnior*
}

Resumo: O presente artigo tem por objetivo comparar duas obras literárias, a saber: Os Vagabundos Iluminados de Jack Kerouac e Sidarta de Hermann Hesse, analisando a maneira como elas utilizaram as fontes budistas e como a tradução literária revela os usos ocidentais dessas mesmas fontes, e também a maneira como o conceito de indivíduo, em uma perspectiva mausseana, é tratado por elas.

Palavras-Chave: Literatura Comparada, budismo, religião, individualismo, ocidente.

A veces en las tardes una cara nos mira desde el fondo de un espejo;

el arte debe ser como ese espejo que nos revela nuestra propia cara.

Jorge Luís Borges - Arte Poética

\section{Introdução}

Hermann Hesse, último baluarte do Romantismo, um narrador com alma de poeta e estilo elegante, e Jack Kerouac, verborrágico e moderno beatnik, de estilo espontâneo e mais focado no conteúdo que na forma. As diferenças entre os dois são um prato cheio para qualquer estudo de Literatura Comparada, muito mais pelos contrastes do que por qualquer semelhança. Porém, existe pelo menos um elemento capaz de aproximá-los: o interesse pelo Budismo - no caso de Kerouac, uma paixão e a intenção de transmitir suas experiências e sensações com a religião oriental por meio da estrutura literária ficcional mais difundida no ocidente: o romance.

Os estudos de Literatura Comparada, outrora um ramo da historiografia literária, apresentam-se modernamente como uma área multidisciplinar, interessada não apenas no fenômeno literário em si, mas em evocar diferentes campos das ciências

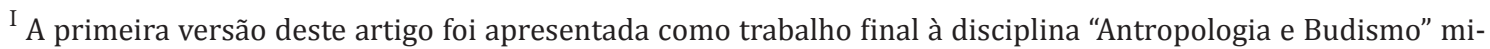
nistrada, no primeiro semestre de 2011, pela professora Ana Cristina Lopes Nina, a quem agradeço. Agradeço também aos pareceristas pelos comentários, considerações e indicações bibliográficas, e à Patricia Cristina Rodrigues pelas orientações técnicas.

* Graduando em Ciências Sociais - USP.
} 
humanas a fim de aprofundar e enriquecer o procedimento analítico, conforme esclarece Carvalhal (1991, p. 11):

comparar não é justapor ou sobrepor, mas é, sobretudo, investigar, indagar, formular questões que nos digam não somente sobre os elementos em jogo (o literário, o artístico), mas sobre o que os ampara (o cultural, por extensão, o social).

Nesse sentido, este artigo procura cotejar o elemento religioso nas obras literárias em questão, utilizando a teoria antropológica como um "catalisador", já que ela formula postulados altamente relevantes para o aspecto analisado. Não se pretende, porém, esgotar o assunto, mas apenas demonstrar que é possível levantar aspectos instigantes e até chegar a algumas conclusões interessantes por meio desse tipo de levantamento multidisciplinar.

Sidarta de Hermann Hesse foi publicado em 1922 e, assim como outras obras do autor, sempre volta à tona quando o ocidente se vê em crise com seus valores materialistas e busca respostas na inesgotável fonte espiritual e filosófica do oriente. Clarke (1997) analisa cuidadosamente esse fenômeno, mostrando como "ondas" de orientalismos alimentaram o século XX com novos olhares e perspectivas. Foi assim no período pós Primeira Guerra, quando o romance veio a público e também nos anos 60, nos EUA, durante a crise do Vietnã. Atualmente o interesse por esse autor entre as camadas mais jovens também vem se intensificando.

Os vagabundos iluminados de Jack Kerouac foi publicado em 1958, um ano antes do início do conflito no Vietnã, e é uma das obras mais lidas do autor - atrás apenas de On the road (1957), considerada a "bíblia hippie" - mas com certeza, juntamente com os escritos de Allan Watts, Allen Ginsberg e Gary Snyder, é um dos principais elos literários entre o pensamento budista e a ideologia hippie que se expandiram na década de 60. Assim como em Hesse, a obra contém uma série de críticas ao materialismo e, dessa forma, continua despertando interesse entre os que buscam alternativas para os valores baseados no individualismo e utilitarismo predominantes no ocidente.

Geralmente as análises feitas sobre o budismo nessas duas obras tendem a dois extremos: pode-se interpretá-lo como uma visão "alienada" do mundo, já que propõe uma atitude introspectiva e até escapista em relação à vida e, dessa forma, incentivaria uma postura contrária ao enfrentamento dos problemas históricos em nome de uma trajetória pessoal de iluminação; ou ao contrário, também se costuma 
interpretá-lo como índice máximo de rebeldia e crítica ao status quo, como pensamento panfletário pela paz mundial. Essas duas tendências podem ser rapidamente vislumbradas na análise panorâmica feita por Otto Maria Carpeaux, na orelha da edição brasileira de Sidarta, em 1974:

O budismo de Hesse não é quietista nem evasionista; seu livro Viagem ao Oriente (Die Morgenlandfahrt) é mesmo um dos mais rebeldes que escreveu. Tampouco tem pontos de contato com o budismo ginástico que foi descoberto pelos beatniks americanos, "rebeldes sem causa". A rebelião de Hesse tem causa: é a paz do mundo, a externa e a interior.

A presente análise deverá evitar um extremo e outro, pois o caminho pretendido é o das fontes budistas presentes nos romances. Dessa forma, a intenção é iluminar alguns aspectos na rede de afinidades que existe entre as duas obras e entre o pensamento budista e ocidental, observando de que maneira certos elementos da religião do Tibete são utilizados por esses dois artistas ocidentais em dois períodos e em dois estilos bem diferentes. Embora algumas considerações estéticas surjam aqui e ali, elas só serão observadas na medida em que lançarem luz sobre o diálogo cultural, foco deste exame.

\section{Sidarta}

O romance Sidarta é conhecido como o resultado de uma viagem empreendida pelo alemão Hermann Hesse pela Índia em 1910, quando o autor entrou em contato direto com a história do Buda Gautama, com a filosofia budista e com a tradição hinduísta. Apesar do nome do protagonista e do título parecer se referir diretamente ao Sakiamuni, ou seja, o Buda Gautama, figura central da religião budista; o Sidarta do livro é outro indivíduo, que vive sua trajetória paralelamente ao xará histórico. A estratégia do autor foi contar uma história fictícia paralela e entrelaçada à história consagrada a fim de expressar livremente seu ponto de vista a respeito da "iluminação", sem precisar ficar preso à narrativa mítica original e correndo menos risco de ferir quaisquer princípios religiosos.

A obra é narrada em estilo solene, típico das histórias sagradas, por um narrador onisciente, como podemos observar logo nas primeiras linhas:

À sombra da casa, ao sol da ribeira, perto dos barcos, na penumbra do salgueiral, ao pé da figueira, criou-se Sidarta, belo filho de brâmane, jovem falcão, junto com Govinda, seu amigo, filho de brâmane (HESSE, 1976[1922], p. 5). 
A narrativa é pontuada por descrições ricas, carregadas de impressões sensoriais, que levam a imaginação do leitor a um oriente atemporal, e que encontra correspondências e ecos na imaginação ocidental:

Enquanto passeava pelas sendas rosadas do figueiredo, enquanto se mantinha sentado na
penumbra azulada do bosque da contemplação, enquanto abluía o corpo no cotidiano ba-
nho expiatório, ou fazia sacrifícios rituais no mangueiral envolto em sombras profundas, fa-
zendo gestos de primorosa correção, despertando amor em toda gente, deliciando a todos,
não sentia, ainda assim, nenhuma satisfação em sua própria alma (HESSE, 1976[1922], p. 6).

E também por monólogos interiores do protagonista em discurso indireto livre, que desde as primeiras páginas retratam a angústia que o moverá durante sua trajetória:

Começava a vislumbrar que seu venerando pai e seus demais mestres, aqueles sábios brâmanes, já lhe haviam comunicado a maior e a melhor parte dos seus conhecimentos: começava a perceber que eles tinham derramado a plenitude do que possuíam no receptáculo acolhedor que ele trazia em seu íntimo. E esse receptáculo não estava cheio; o espírito continuava insatisfeito; a alma andava inquieta; o coração não se sentia saciado. As abluções, por proveitosas que fossem, eram apenas água; não tiravam dele o pecado; não curavam a sede do espírito; não aliviavam a angústia do coração. Excelentes eram os sacrifícios e as invocações dos deuses - mas que lhe adiantava tudo isso? Propiciariam os sacrifícios a felicidade? (Hesse, 1976[1922], p. 7).

Na obra, Sidarta é um brilhante filho de brâmane com uma carreira promissora que, insatisfeito com o vazio das liturgias religiosas, as quais para ele estão aquém do verdadeiro sentido do Atman - princípio sagrado no hinduísmo, algo como "essência divina" - resolve abandonar tudo e juntar-se aos ascetas samanas, no que é seguido por um companheiro fiel e amigo de infância: Govinda. Porém, mesmo entre os samanas, Sidarta desconfia que as práticas ascéticas não cumprem o que prometem, pois suas técnicas levam ao esquecimento do próprio eu, mas com resultados pouco duradouros. É então que ouvem falar do iluminado Gotama, este sim o próprio Buda Sakiamuni, e resolvem seguir ao seu encontro. Após ouvir o dharma - o conhecimento, a lei - Govinda resolve aceitar e seguir a nova doutrina; mas Sidarta, mesmo percebendo que tudo o que o iluminado dizia exalava a verdade mais pura, sentia que tudo aquilo só podia ser alcançado por meio da vivência pessoal e não pelo conhecimento; então ele parte mais uma vez. Logo decide não buscar mais nenhum mestre e viver a sua própria experiência individual, olha ao redor e se sente mais vivo do que nunca, como se o mundo surgisse naquele momento. Eis que então 
conhece a prostituta Kamala e é através dela que ele conhecerá o mundo e suas delícias: o Sansara - o mundo material, na verdade o fluxo de mortes e renascimentos da natureza. Em seguida, consegue emprego com um comerciante rico e aprende a comer em demasia, a tomar vinho, a jogar e a amar, até quase deixar de ouvir a sua voz interior. Nesse ponto de sua história, ao pé de sua mangueira, em seu jardim, sente a inutilidade e o vazio do ato de possuir "coisas" e resolve mais uma vez partir. Pensa em se matar atirando-se em um rio, mas quando vislumbra suas águas resolve proferir o $\mathrm{Om}$ - o mais importante mantra do hinduísmo, o "som do universo" - então se acalma e dorme. Na manhã seguinte, após um breve reencontro com o monge budista Govinda, que não o reconheceu em suas roupas de rico comerciante, desce o rio até a casa do barqueiro viúvo Vasudeva e decide estabelecer-se com ele e, como ele, tornar-se um discípulo do rio. Ali Sidarta envelhece, mas sua trajetória ainda terá uma surpresa. Kamala, agora convertida ao budismo, atravessa o rio para prestar culto ao falecido Gotama e traz consigo o filho de seu relacionamento com Sidarta, porém, devido ao ataque de uma serpente, Kamala morre, deixando a criança com os barqueiros. Nesse momento, Sidarta sofre sua maior provação: o amor; pois é pelo filho, mimado e ingrato, que o protagonista sentirá mais intensamente esse sentimento. 0 menino, insensível à bondade e humildade do pai e com saudade dos luxos que possuía, após inúmeras humilhações que infringiu ao seu pobre velho, foge. Sidarta tenta procurá-lo, mas é dissuadido pelo amigo Vasudeva que relembra o fato de que o próprio Sidarta também abandonou seu pai quando iniciou sua busca. Quando Sidarta finalmente se resigna com a inutilidade de seus esforços para agradar ou preservar o filho, Vasudeva parte para a floresta e Sidarta vê, em seu semblante, a calma iluminada que reconhecera no Buda Gotama. Sidarta então permanece em sua atividade cotidiana, de uma margem a outra do rio, até que, certo dia, Govinda vem procurá-lo porque ouviu falar de um barqueiro que também era um grande sábio, sem saber que se tratava de seu antigo amigo de infância. Após reconhecê-lo e conversar com ele, Govinda reconhece o mesmo sorriso que vira no Buda, o sorriso de quem encontrou a paz.

\section{Os vagabundos iluminados}

A obra é um romance autobiográfico em primeira pessoa como a maior parte das obras de Jack Kerouac. A estrutura e o estilo lembram um diário de viagem em que o sublime, o cotidiano e o grotesco se misturam de uma forma muito natural. 
Muitos dos diálogos e dos contatos com outros personagens são efêmeros e fragmentários e a realidade se mostra de uma maneira muito mais crua e "suja", sem o sentido de totalidade que encontramos em Hesse, onde todos os encontros e todas as falas possuem uma relação com o leitmotiv da história.

Em um dia qualquer do final de setembro de 1955, bem ao meio dia, peguei um trem de carga que saía de Los Angeles, subi em um vagão aberto e deitei com a cabeça apoiada na minha sacola, com os joelhos cruzados, e fiquei contemplando as nuvens enquanto viajava em direção ao norte, para Santa Bárbara (KerouAC, 2010[1958], p. 7).

No romance, Ray Smith, alter ego do autor, viaja como clandestino pelas estradas de ferro que cortam os Estados Unidos e, nessas andanças, acaba conhecendo o jovem montanhista e budista Japhy Rider (Gary Snyder) que, apesar de mais jovem, será seu mestre de budismo-zen e de escalada.

Não há uma forma estrutural do tipo "apresentação-complicação-clímax" típica do romance tradicional; as ações se acumulam em uma miscelânea que envolve as figuras humanas encontradas nas caronas pelas estradas e os jovens amigos do narrador, beatnik's e excêntricos, que lhe dão abrigo nos momentos de pouso; além de festas orgiásticas, contato com a natureza, escaladas e sessões de meditação. Chama a atenção a forma como se entrelaçam bebedeiras, sexo e rock'n'roll com as mensagens budistas, sutras e comportamento ascético. Entretanto, pode-se resumir tudo com a expressão do título: "vagabundo do dharma" (The Dharma Bums, no original), seres que vislumbraram a inutilidade das convenções materialistas, independentemente de sua compreensão ou conhecimento sobre o budismo. Parece que o narrador inclui nessa categoria qualquer andarilho que comungue com um ideal de simplicidade, negação do individualismo e da busca por prazeres materiais.

Então, após atravessar os Estados Unidos, passar pelo México, correr riscos, fazer amizades e visitar rapidamente a família, Ray Smith despede-se de Japhy, que parte para um mosteiro no Japão, e obedecendo a seus conselhos e orientações, passa um verão inteiro sobre as montanhas, como vigia de incêndio de uma reserva natural no norte dos Estados Unidos, e na solidão eterna das alturas tem sua epifania.

\section{As fontes budistas e sua caracterização nas obras}

Hermann Hesse bebeu diretamente de fontes hinduístas, mas ao contrário do que se poderia esperar, sua obra tem uma universalidade que transcende a identi- 
ficação com qualquer corrente específica das variantes do budismo existentes. Conceitos-chave como Atman, Sansara, Buda e Nirvana, que já não eram completamente estranhos ao Ocidente, são tratados e explicitados de maneira que qualquer leitor ocidental possa se identificar e se reconhecer neles, pois o autor apresenta-os utilizando uma linguagem e imagens familiares ao público europeu. Dessa forma, seu romance se descola do próprio budismo/hinduísmo enquanto sistemas religiosos, mas é profundo enquanto transmissor do pensamento budista/hinduísta.

Diferentemente, em Os vagabundos iluminados, duas vertentes do budismo são representadas por seus personagens principais. Ray/Kerouac, o narrador, se identifica com o budismo mahayana - vertente tibetana, mais ritualizada, mais "colorida" por mitos, divindades e formas rituais - e enxerga relações entre esta vertente e o cristianismo herdado por sua educação familiar; nesse sentido, o personagem também tem uma preferência por uma prática ritualizada e consegue enxergar, em manifestações do cristianismo, mensagens legítimas do dharma. Já Japhy/Snyder, seguidor da doutrina Zen japonesa, não vê sentido nas relações com o cristianismo ou nas manifestações muito ritualizadas, e se concentra basicamente na meditação contemplativa da natureza, possivelmente também por motivos pessoais de origem, pois viveu sua infância em um rancho afastado e em contato íntimo com a floresta. Os diálogos entre Ray e Japhy, em diversos momentos, evidenciam essa disparidade. Neste excerto, Japhy pergunta:

Você gosta mesmo de Cristo, não é?

Claro que gosto. E, afinal, muita gente diz que ele é Maitreya, o Buda profetizado a aparecer depois de Sakyamuni, você sabe, Maitreya significa 'Amor' em sânscrito e Cristo só falava de amor.

Ah, não vai começar a pregar o cristianismo para cima de mim [...] (KERouAC, 2010 [1958], p. 208).

Cabe ressaltar que entre os beat generation como o próprio Snyder e também Ginsberg o contato mais intenso com o budismo se deu justamente com a vertente Zen-japonesa, através dos escritos e ensinamentos de D.T. Suzuki e seus Essays in Zen Buddhism, publicados nos Estados Unidos em 1927. Entretanto, em entrevista para a revista The Paris Review, publicada em 1968, Kerouac afirmou serem outras as suas fontes:

What's really influenced my work is the Mahayana Buddhism, the original Buddhism of Gautama 'Sàkyamuni, the Buddha himself, of the India of old [...] Zen is what's left of his Buddhism, or Bodhi, after its passing into China and then into Japan (BERRIGAN, 1968). 
Tais diferenças de concepção acabam por revelar a variedade que existe dentro do budismo, mas também o fato de que o homem ocidental, mesmo se inclinando para uma religião que tem por princípio a anulação do ego, tende a buscar a vertente que melhor se adapta a suas inclinações individualistas. Também é necessário considerar que após as reflexões de Mauss (2006[1938]) sobre o a noção de pessoa e de "eu", compreender a negação da individualidade possui significados diferentes em contextos diversos. Em seu artigo "Uma categoria do espírito humano: a noção de pessoa, a de 'Eu'", Mauss afirma que, apenas no ocidente, essa trajetória histórica implicou no "ser indivisível e moral" que acreditamos, erroneamente, ser intrínseca a toda condição humana.

Para Mauss, a partir do sentido primordial de "máscara", em Roma, desenvolveu-se a "persona" como caráter jurídico, ou seja, como direito das famílias nobres de se identificarem a uma casa, a um "nome", então persona começa a adquirir o sentido de "verdadeira natureza do indivíduo". Com o cristianismo, a persona é dotada de consciência e, assim, de unidade; finalmente, as considerações filosóficas de Descartes, Hume, Kant e Fichte, respectivamente, acrescentaram à complexidade do "Eu" o ser psicológico, como condição da consciência e da ciência: cogito ergo sun. Logo, nossa concepção ocidental de "pessoa", teria se formado há apenas dois séculos, e ainda estaria em processo.

Em Sidarta também encontramos uma busca individualista no centro da obra - engenhosamente construída em torno de uma estratégia narrativa que busca a identificação do leitor. A grande diferença na trajetória do Buda Gautama com o fictício Sidarta está na inversão da ordem das experiências dos personagens. É sabido que Gautama foi um príncipe que vivia cercado de prazeres, sem saber o que era dor, doença, morte ou velhice, e quando descobriu esses elementos de degradação, partiu em busca de sua cessação, tornando-se um asceta antes de alcançar a iluminação. Pois bem, Sidarta segue um caminho invertido, como descrito no resumo anterior, ele primeiramente é brâmane, depois asceta e só depois de ouvir o precioso dharma do Iluminado é que segue para a vida de prazeres. Para um budista, é como se os "atos" da vida de Buda se manifestassem às avessas, mas para o leitor ocidental o efeito de identificação é muito forte, pois o narrador descreve em detalhes as delícias experimentadas pelo protagonista durante sua vida adulta, que as valoriza e vai se encantando com elas; tal valorização está em consonância com a tradição grego-romano na raiz do ocidente: a elevação do corpo físico, do amor erótico, do 
universo dos sentidos, tão bem expressados pela temática horaciana do carpe diem e também por dramas sociais muito comuns para o ethos ocidental, principalmente nas primeiras décadas do século XX: uma infância e adolescência marcadas pela educação religiosa rígida e por crises místicas, e um encontro com um mundo de dissoluções e de valorização das liberdades individuais no início da vida adulta.

Entretanto, no caso de Sidarta, a própria experiência do Materialismo e do mundo das delícias do Sansara acaba se esvaziando, quase levando o personagem à destruição. Diferentemente de Sakiamuni, que abandona o palácio por compaixão pelas criaturas que sofrem, Sidarta abandona seu palacete porque o mundo da fruição dos prazeres esgotou-se como sentido para sua busca pessoal, ou seja, uma razão centrada na sua busca individualista por iluminação.

Aqui também podemos fazer outras considerações. Hesse, em sua narrativa, faz com que Sidarta siga exatamente os quatro estágios da vida segundo o hinduísmo, os Ashramas: Brahmacharya ou pastar em Brahma (dos 0 aos 24 anos), período de aprendizado e abstinência em que se pratica a autodisciplina e se aprende o dharma e a meditação; Grihasthya ou Samsara (dos 25 aos 49 anos), estágio em que se forma família e se obtém uma carreira profissional; Vanaprastha ou Sannyasin (dos 50 aos 74 anos), momento em que o homem deve viver como eremita, voltando à abstinência e buscando a vida espiritual; e, por último, a fase Sanyasa (75 aos 100 anos) quando o homem se liberta da vida material e abraça a medição definitivamente. Mas também, ao passar por essas fases, Sidarta não apenas as cumpre, como também experimenta a idiossincrasia de caminhos opostos, como se a plenitude, a totalidade só pudesse ser alcançada com a experimentação de todos os dualismos e contradições.

Kuschel (1991), analisando a biografia religiosa de Hesse, percebeu uma dinâmica de crises e reconciliações místicas repercutindo em suas obras, e classificou Sidarta como um dos momentos de apaziguamento entre as origens pietistas do autor, os estudos hinduístas (seu avô materno e seus pais eram estudiosos e entusiastas da cultura indiana) e suas angústias pessoais que o levaram, na adolescência, a desfraldar seu niilismo. Assim, o amor universal que tudo aceita e absorve pode ser entendido como a chave para a iluminação do protagonista que, diferentemente do seu amigo Govinda, não se contenta com a contemplação do mundo, mas busca abraçá-lo e vivenciá-lo em todos os conflitos existenciais. O próprio Hesse destacou: 
com o cristianismo e marcam até mesmo um traço verdadeiramente protestante (ZeLLER apud Carandell, 19??, p. 149).

0 "amor" aqui só faz sentido em sua acepção mais universal; como Cristo abraça a cruz por amor, Sidarta abdica do conhecimento para viver intensamente as contradições do Sansara. Assim, o materialismo no mito do Buda e em Sidarta são questionados e abandonados de maneiras diferentes: pela compaixão ao próximo, no primeiro e pelo esvaziamento e desencanto, no segundo. A compaixão fez Buda ir buscar o conhecimento capaz de livrar o homem da morte e, no caso de Sidarta, foi o conhecimento que o levou à compaixão (e ao amor), ou seja, a mergulhar no abismo do Sansara.

Com relação ao cristianismo, na mesma entrevista à The Paris Review, Kerouac, ao ser questionado por que escrevia sobre Buda e não sobre Jesus, respondeu que só escrevia sobre Jesus; quando o entrevistador então perguntou qual era diferença entre Jesus e Buda, sua resposta foi, simplesmente: "That's a very good question. There is no difference" (BERRIGAN, 1968).

Esses autores, em sua postura contrária ao materialismo e ao individualismo ocidentais, criaram narrativas inspiradas em uma cultura e em uma religião que busca justamente negar esse indivíduo materialista. Porém, ao fazê-lo, sincretizaram Buda e Jesus, e trouxeram à baila a cultura e a religião que, na perspectiva de Mauss, contribuíram de maneira decisiva para a formação da própria noção de indivíduo. A questão é: teria esse procedimento empreendido uma espécie de giro de 360 graus? Em outras palavras, para fugir do materialismo individualista, buscaram a compaixão por tudo quanto existe (ou não existe na perspectiva budista), mas essa mesma compaixão só pode se manifestar a partir de um indivíduo determinado no tempo e no espaço e em sua existência pessoal e indivisível.

Em Kerouac essa questão fica ainda mais evidente quando percebemos as tensões existentes entre a necessidade da austeridade e da disciplina monástica, para negação e controle das vontades, e o impulso hedonista das festas, drogas e bebedeiras, o que, conforme ilustra Clarke (1997, p.104), foi avaliado como distorções e incompreensões dos ensinamentos originais. Com relação ao sentimento de comunhão ou compaixão com o mundo, ainda na entrevista à The Paris Review, quando Kerouac foi perguntado se havia algum senso de comunidade entre os da geração Beat, sua resposta foi:

That community feeling was largely inspired by the same characters I mentioned, like Ferlinghetti, Ginsberg; they are very socialistically minded and want everybody to live 
in some kind of frenetic kibbutz, solidarity and all that. I was a loner. Snyder is not like Whalen, Whalen is not like McClure, I am not like McClure, McClure is not like Ferlinghetti, Ginsberg is not like Ferlinghetti, but we all had fun over wine anyway. We knew thousands of poets and painters and jazz musicians. There's no "Beat crowd" like you say [...] What about Scott Fitzgerald and his "lost crowd," does that sound right? Or Goethe and his "Wilhelm Meister crowd"? The subject is such a bore. Pass me that glass. (BERRIGAN, 1968).

Kerouac reconhece: há sentimentos comunitários, mas também cada integrante da "Beat crowd" é único, é um indivíduo com suas próprias preocupações estéticas, seu estilo, sua consciência. Cabe ressaltar que esse espírito da contracultura beatnik não era fruto apenas da importação de doutrinas orientais, mas também era alimentado pelo pensamento crítico antiburguês provindo das obras de autores como Walt Whitman e Fiódor Dostoiévski.

Mas a ênfase no indivíduo também é perceptível em Hesse. Em uma análise minuciosa sobre a recepção crítica do autor alemão no Brasil, Souza (2007) mostra que a questão do individualismo é ponto pacífico em quase todas as análises sobre esse escritor, e exemplifica com um artigo de Pedro Moacyr Campos de 1958:

\footnotetext{
Praticamente toda a obra de Hesse está impregnada deste princípio de aceitação incondicional da existência, da vida permanentemente em mutação, em "werden", sem outro motivo para o homem além de sua autoformação, através de provações, através de contínuas experiências, pelas quais se distribuem as etapas de realização individual (CAmpos apud Souza, 2007, p. 29).
}

No budismo, o sentimento de compaixão não tem a mesma centralidade como no cristianismo, mas é, tanto em Sidarta quanto em Os vagabundos iluminados, parte essencial da busca dos protagonistas. Grosso modo, para o budismo, a Iluminação se alcança por meio da contemplação e da meditação; a compaixão é valorizada de formas diferentes pelas diversas correntes budistas existentes; por exemplo, é importante para a vertente Mahayana, mas nem tanto no budismo Theravada. No caso do cristianismo, o amor ao próximo e a compaixão fazem parte do próprio caminho para a salvação, e é pré-requisito essencial.

Logo, estamos lidando com o indivíduo de moral cristã, ou melhor dizendo, com a "camada moral" do indivíduo formada pelo cristianismo no ocidente, de acordo com Mauss. Dessa forma, o budismo aparece muito mais como um ponto de vista a partir do qual se pode reavaliar a noção de "Eu" sem que seja necessária uma adesão completa a seus dogmas. Vejamos a concepção de Mauss sobre a formação da noção de indivíduo na Índia: 
A Índia parece-me ter sido a mais antiga das civilizações que teve a noção do indivíduo, de sua consciência, digo eu, do "Eu"; a ahamkara, a "fabricação do eu", é o nome da consciência individual, ahan = eu (é a mesma palavra indo-europeia que ego). A palavra ahamkara é evidentemente uma palavra técnica, criada por alguma escola de sábios videntes, superiores a todas as ilusões psicológicas. 0 samkhya, a escola que justamente deve ter precedido o budismo, afirma o caráter composto das coisas e dos espíritos (samkhya quer dizer precisamente composição), considera que o "Eu" é algo ilusório; quanto ao budismo, numa primeira parte de sua história, ele decretava ser esse apenas um composto, divisível, separável de skandha, e buscava seu aniquilamento no monge (MAUSs, 2006[1938], p. 383).

Assim, a noção de indivíduo, no oriente, foi construída para ser destruída, enquanto no ocidente ela foi amplificada ao receber novas camadas de significação a ponto de perder sua origem histórica e se dissolver no senso comum, como se fosse algo latente à própria existência humana.

Dessa maneira, é razoável imaginar que algum contato da visão de mundo hinduísta/budista com o ocidente, mesmo que não seja tão profunda a ponto de possibilitar a negação da noção de "Eu" ou de indivíduo, serve ao menos como elemento desnaturalizador dessa noção. Tal desnaturalização permite que se visualize o indivíduo sob outros prismas: o da possibilidade e o da transitoriedade, e isso permite aos protagonistas de Hesse e Kerouac a possibilidade da "peregrinação", ou seja, a fuga de uma realidade massificante em busca de sua trajetória pessoal. Sim, pois tanto para Sidarta como para Ray, a angústia não nasce tanto da dúvida com relação a real existência do "Eu”, mas da alienação do indivíduo em uma sociedade capitalista e de consumo generalizado, que reduz o indivíduo a mera existência materialista. Observemos o momento em que Sidarta se dá conta do vazio de sua vida como administrador abastado:

\begin{abstract}
Ainda se mantinha sentado, quando caiu a noite. Enquanto levantava os olhos e deparava com as estrelas, pensou: "Aqui estou, ao pé da minha mangueira, no meu jardim". E esboçou um leve sorriso, ao ponderar se era necessário, importante e certo, e não apenas um brinquedo tolo possuir uma mangueira e um jardim? (HESSE, 1976[1922], p.70).
\end{abstract}

E comparemos com uma das falas de Japhy/Snyder, quando, em meio a uma noite de bebedeira, delírios e poemas surreais, ele praticamente profetiza a chegada do movimento hippie:

Vagabundos do Darma, que se recusam a concordar com a afirmação generalizada de que consomem a produção e portanto precisam trabalhar pelo privilégio de consumir, por toda aquela porcaria que não queriam, como refrigeradores, aparelhos de TV, 
carros, pelo menos os carros novos e chiques, certos óleos de cabelo e desodorante e bobagens em geral que a gente acaba vendo no lixo depois de uma semana, todos eles aprisionados em um sistema de trabalho, produção, consumo, trabalho, produção, consumo, tenho a visão de uma grande revolução de mochilas, milhares ou até mesmo milhões de jovens americanos vagando por aí com mochilas nas costas (KEROUAC, 2010[1958], p.102).

É bom ressaltar que essas críticas ao materialismo tiveram fortes repercussões em movimentos de contracultura nos países dos autores, na Alemanha com o Jugendbewegung nos anos 20, e com o movimento hippie dos anos 60 nos Estados Unidos.

Assim encontramos, nos dois romancistas, a mesma imagem arquetípica: $o$ peregrino. Personagens que percorrem longos caminhos físicos e espirituais vão dialogando com a paisagem e com os eventos que encontram e que os encontram, para, enfim, mergulharem tão profundamente na descoberta de seus "eus" que acabam por superá-los, por transcendê-los e também à própria realidade que os cerca. É a própria história do Buda, recontada, em essência. Curiosamente, o metódico e contemplativo Sidarta vai encontrar sua iluminação no leito de um rio, imagem simbólica da passagem e da constante inconstância do mundo; enquanto o inquieto e verborrágico Ray encontrará a paz sobre uma montanha, símbolo de eternidade e solidão. Coincidência ou não, os argumentos das duas obras utilizam imagens complementares como o elemento que revela aos personagens a experiência do todo para, em seguida, tomarem consciência do vazio. Este que é um conceito budista dos mais viscerais e difíceis de traduzir para o Ocidente materialista, já que é a mais radical negação da matéria. Vejamos como os autores o traduzem nos momentos finais de suas obras:

Será que somos anjos caídos que não quiseram acreditar que o nada é nada e portanto nascemos para perder aqueles que amamos e os amigos queridos um por um e afinal a nossa própria vida, para ter essa comprovação? [...] Mas a manhã fria retomava, com nuvens escapando da garganta Lightning como se fossem uma fumaça gigante, o lago lá embaixo sempre de um cerúleo neutro, e o vazio o mesmo de sempre. Ó dentes da terra que rangem, para onde tudo isso nos levaria a não ser para alguma eternidade dourada, para comprovar que sempre estivemos errados, para comprovar que a comprovação em si mesma não valia nada [...] (KerouAC, 2010[1958], p.247).

Talvez seja essa a razão por que não encontres a paz: o excesso de palavras. Pois, Govinda, também a redenção e a virtude, o Sansara e o Nirvana são meras palavras. Não existe coisa alguma que seja Nirvana. O que existe é a palavra Nirvana (HESSE, 1976[1922], p. 116). 
O conceito é tão complexo que são necessárias páginas e mais páginas dos romances para se tentar transmiti-lo. Em Kerouac, o próprio Ray tenta, por várias vezes, explicar para alguns de seus amigos e também para seus familiares o que é o vazio e como ele é a única coisa que é, mas sempre sem sucesso, e mesmo para o leitor, o trecho mais esclarecedor é esse que se encontra nas páginas finais. Também Sidarta, ao entrar em contato com o dharma do Iluminado, apesar de compreender e reconhecer a verdadeira doutrina, afasta-se da vida monástica em busca de um aprendizado empírico. Não há, portanto, uma conclusão simples sobre essa "iluminação" sentida pelos protagonistas. Nirvana? Mokhsa? Resignação niilista? Nas últimas páginas de Sidarta, não temos mais acesso às angústias do protagonista, pois parecem que as mesmas cessaram, e só com o reaparecimento de Govinda é que podemos, por meio de sua percepção, saber do sorriso perfeito que Sidarta manifesta: sorriso que abarca um dualismo apaziguador e perturbador ao mesmo tempo:

\begin{abstract}
E Govinda percebeu que esse sorriso da máscara, o sorriso da unidade acima do fluxo das aparências, o sorriso da simultaneidade muito além do sem-número de nascimentos e mortes, o sorriso de Sidarta, era idêntico àquele sorriso calmo, delicado, indevassável, talvez bondoso talvez irônico, de Gotama, o Buda, tal como ele próprio o observara centenas de vezes com profundo respeito. Era assim - Govinda o sabia - que sorriam os seres perfeitos (HESSE, 1976[1922], p.120).
\end{abstract}

Mas o sentido desse sorriso não nos é revelado plenamente. Da mesma maneira, ao se despedir de sua montanha e do barraco que o abrigou durante o verão, Ray descreve, nas últimas linhas do romance:

[...] voltei-me e ajoelhei na trilha e disse: "Obrigado, barraco". E depois acrescentei: "Blá", com um sorrisinho, porque eu sabia que aquele barraco e aquela montanha compreenderiam o que aquilo significava, e me virei e continuei seguindo a trilha que me conduziria de volta a este mundo (KerouAC, 2010 [1958], p. 252).

E esse outro sorriso e essa interjeição que só a montanha e o barraco podem compreender? 0 que significam? Ambos os romances concluem-se no limite do que se torna inominável.

\title{
Conclusões finais
}

É temerário fazer interpretações sobre a intenção que move um artista, mas levando em consideração que eles escolheram o romance para transmitir suas leituras particulares sobre a filosofia budista; que o romance possui um poder de divulgação 
e penetração no ocidente maior do que qualquer outra forma narrativa, e também que graças a esse tipo de divulgação, muitos convertidos ao budismo tiveram o seu primeiro contato com essa religião/filosofia, não seria tão extravagante afirmar que o romancista que se propõe a tão intensa expressão do dharma procura agir como um verdadeiro bodisatva - pessoa sábia que busca ajudar os outros seres do mundo a se tornarem livres das ilusões do sansara - e isso se pode afirmar com certeza no caso de Kerouac que também escreveu uma biografia de Buda com intenções declaradamente doutrinárias - Despertar: uma vida de Buda (2010 [2008]).

Entretanto, apesar de os textos sagrados do budismo também utilizarem formas narrativas para enunciar o dharma, ao se comparar as narrativas míticas do Buda Gautama com os dois romances modernos, temos que levar em consideração o mesmo tipo de relação que Lukács (1916) fez entre as epopeias antigas e o romance. Há nas epopeias, como nos textos sagrados tradicionais do budismo, uma totalidade nos personagens, personalidades "acabadas" e linearmente construídas; enquanto no romance, após a ruptura moderna entre o sujeito e o mundo, o que através de Mauss (1938) podemos relacionar com a criação do sujeito psicológico, predominam personagens incompletos e angustiados, em busca de sua totalidade, exatamente como Sidarta e Ray Smith. Tais personagens refletem certos antagonismos e paradoxos da prática ocidental do budismo, pois a concepção do "Eu" no Ocidente admite complexidades de tal ordem que, no mais das vezes, através das práticas como a psicanálise ou da autoajuda, procura-se muito mais a construção ou compreensão desse "Eu". 0 budismo, ao entender essa individualização como uma ilusão do Samsara, opõe-se à noção de indivíduo e busca negá-lo por meio do conceito de vazio. No ocidente, essas concepções encontram consonância com a crítica ao individualismo, mas até que ponto essa negação não passa de uma marca individual, muitas vezes, de rebeldia? Se entendermos o "Eu" como uma construção histórica dinâmica, então tentar negá-lo pode refletir inúmeros significados.

\section{Referências}

BERRIGAN, T. (et. al). (1968). Jack Kerouac: the art of fiction: entrevista com Jack Kerouac. The Paris Review. Disponível em: <http://www.theparisreview.org/interviews/ 4260/the-art-of-fiction-no-41-jack-kerouac>. Acesso em 10 abr. 2012.

Carandell, J. M. (19??). Conhecer Hermann Hesse. Lisboa,Ulisseia.

Carvalhal, T. F. (1991). "Literatura Comparada: a estratégia interdisciplinar". Revista brasileira de Literatura Comparada, Niterói, Abralic, n. 1, p. 9-21. 
Clarke, J. J. (1997). "Orientalism in the twentieth century". Oriental enlightenment: the encounter between Asian and Western thought. London, Routledge.

Hesse, H. (1976[1922]). Sidarta. Tradução de Herbert Caro. 12ª e 16ª edições. Inclui orelha de Otto M. Carpeaux (1974) e prefácio de Luiz Carlos Maciel. Rio de Janeiro, Civilização Brasileira.

Kerouac, J. (2010[1958]). Os vagabundos iluminados. Porto Alegre, L \& PM Pocket. (2010[2008]). Despertar: uma vida de Buda. Porto Alegre, L \& PM Pocket.

KuSCHEL, K. (1999[1991]). "Hermann Hesse e a insondabilidade da alma". In: Os escritores e as escrituras: retratos teológicos literários. São Paulo, Loyola.

LuKÁcs, G. (2009[1916]). A teoria do romance: um ensaio histórico-filosófico sobre as formas da grande épica. São Paulo, Duas Cidades.

MAuSS, M. (2006[1938]). "Uma categoria do espírito humano: a noção de pessoa, a de 'Eu'”. In: . Sociologia e Antropologia. São Paulo, Cosac Naify.

NinA, A. C. L. (2006). Ventos da impermanência: um estudo sobre a re-significação do budismo tibetano no contexto da diáspora. São Paulo, EDUSP.

SouZA, J. P. F. (2007). Um lobo nos trópicos: a recepção crítica de Hermann Hesse no Brasil (1935-2005). Dissertação de mestrado em Letras. Assis, Universidade Estadual Paulista, 296 p.

Recebido em outubro/2011

Aprovado em junho/2012 